\title{
The frequency of NPM1 mutations in childhood acute myeloid leukemia
}

\author{
Maria Braoudaki ${ }^{*}$, Chrissa Papathanassiou ${ }^{2}$, Katerina Katsibardi ${ }^{2}$, Natalia Tourkadoni ${ }^{2}$, Kalliopi Karamolegou ${ }^{2}$, \\ Fotini Tzortzatou-Stathopoulou ${ }^{1,2}$
}

\begin{abstract}
Background: Mutations in the nucleophosmin (NPM1) gene have been solely associated with childhood acute myeloid leukemia (AML). We evaluated the frequency of NPM1 mutations in childhood AML, their relation to clinical and cytogenetic features and the presence of common FLT3 and RAS mutations.

Results: NPM1 mutations were found in 8\% of cases. They involved the typical type ' $A$ ' mutation and one novel mutation characterized by two individual base pair substitutions, which resulted in 2 amino acid changes (W290) and (S293) in the NPM protein. FLT3/ITD mutations were observed in 12\% of the cases and in one NPM1-mutated case bearing also $\mathrm{t}(8 ; 21)$ (q22;q22). No common RAS mutations were identified.

Conclusions: A relatively consistent NPM1 mutation rate was observed, but with variations in types of mutations. The role of different types of NPM1 mutations, either individually or in the presence of other common gene mutations may be essential for childhood AML prognosis.
\end{abstract}

\section{Background}

Acute myeloid leukemia (AML) is a genetically and phenotypically heterogenous disease that accounts for $15-20 \%$ of childhood leukemia [1]. Several genetic mutations, gene rearrangements and chromosomal translocations are involved in the pathogenesis of leukemia. Chromosomal abnormalities like the $t(15 ; 17)$ or the inv $(16)$ have been associated with a particular morphology and clinical behavior [2]. However, in patients with no detectable chromosomal abnormalities, the genetic background remains unknown $[3,4]$. Conversely, previous work has indicated the involvement of various gene mutations with prognostic relevance in AML, including activating mutations of genes encoding transcription factors $(A M L 1, C E B P \alpha)$, tyrosine kinases (FLT3, KIT) or their downstream effectors (NRAS) and nucleophosmin (NPM1) mutations [3,5].

Nucleophosmin is a multifunctional nucleocytoplasmic protein involved in several cellular activities, such as ribosomal biosynthesis, maintenance of genome stability and molecular chaperone functions [6,7]. Abnormal

\footnotetext{
* Correspondence: mbraouda@yahoo.co.uk

${ }^{1}$ University Research Institute for the Study and Treatment of Childhood Genetic and Malignant Diseases, University of Athens, "Aghia Sophia" Children's Hospital, Athens, Greece

Full list of author information is available at the end of the article
}

expression of NPM may lead to the oncogenesis of some types of leukemia as NPM1 gene is a partner in several tumor associated chromosomal translocations [5]. A number of studies have described the presence of common mutations within the final exon (exon-12) of the NPM1 gene in patients with AML [1,5,7-11]. These mutations cause the cytoplasmic localization of NPM and abrogate its function [12].

NPM1 gene mutations have been described in both adult and pediatric patients with variable prevalence and proven to have prognostic significance. NPM1 is mutated in a large proportion (30-50\%) of adult AML cases with a normal karyotype $[8,13]$. This subset of AML patients that exhibit a normal karyotype account for approximately $50 \%$ of cases and thus far have a markedly variable outcome. The NPM1 mutations in AML cases with a normal karyotype have been significantly associated with high frequency of internal tandem duplications of FMSlike tyrosine kinase-3 (FLT3/ITD) [1], which are considered to confer a less favorable prognosis.

The current study was undertaken to evaluate the prevalence of NPM1 mutations in childhood AML in association with cytogenetic analysis, molecular screening of common gene mutations and patients' clinical characteristics, in order to address its prognostic relevance.
C Biomed Central

(c) 2010 Braoudaki et al; licensee BioMed Central Ltd. This is an Open Access article distributed under the terms of the Creative Commons Attribution License (http://creativecommons.org/licenses/by/2.0), which permits unrestricted use, distribution, and reproduction in any medium, provided the original work is properly cited. 


\section{Methods \\ Patient Samples}

A total of 28 pediatric patients were diagnosed with AML within a 10-year period. The patient population comprised primarily of Greek children (24/28), whilst the rest of the cohort included Albanian (3/28) and Romanian (1/28) patients. All patients received chemotherapy according to BFM AML protocol (BFM87; $\mathrm{n}=14$ and BFM04; $\mathrm{n}=11$ ) for 12 months. Patient samples were obtained from bone marrow aspirates at diagnosis. Sufficient amount of DNA for analysis of NPM1 mutations was available in 25/28 (89.3\%) patients at diagnosis. Of those, $18 / 25$ were diagnosed with de novo AML and 7/25 with secondary AML following myelodysplastic syndrome (MDS). The patients' median age was 7 years (range 1-14 years) and among them, $12 / 28$ (48\%) patients were male. The diagnosis was based on the French-American-British (FAB) classification scheme and immunophenotype. The study population included 1 patient with M0, 4 patients with M1, 4 patients with M2, 3 patients with M4, 5 patients with M5 (4M5a and $1 \mathrm{M} 5 \mathrm{~b}$ ) and 1 patient with M6 FAB subtype. This study was approved by the Medical School of the University of Athens in Greece.

\section{Cytogenetic analysis}

Cytogenetic investigations were performed by karyotyping G-banding analysis in all patients. Additionally, interphase fluorescence in situ hybridization (iFISH) was used to monitor chromosomal aberrations.

\section{Molecular analyses of NPM1, FLT3 and RAS mutations}

Genomic DNA was extracted from bone marrow samples according to the standard phenol-chloroform protocol. The exon 12 of the NPM1 gene was amplified using polymerase chain reaction (PCR). The primers and the procedure were adapted from Döhner et al. [14]. Mutational analyses of the FLT3/AL (activation loop) at positions D835/I836, FLT3/ITD and RAS genes (NRAS, HRAS and $K R A S)$ were performed as previously described [15].

\section{DNA sequencing}

Direct sequencing of both strands of each PCR product was carried out on an ABI PRISM 3100-Avant Genetic Analyser (Applied Biosystems, Foster City, CA), according to the manufacturer's instructions. All samples were sequenced, including those that did not provide preliminary evidence for FLT3 mutations based on electrophoresis.

\section{Statistical analyses}

The prevalence of NPM1 mutations in AML was too low to permit statistical analysis for correlation with survival. Actuarial estimates of the event-free-survival (EFS) and overall survival (OS) at 5-years were calculated for $20 / 25$ patients $(5 / 25$ newly diagnosed) using the KaplanMeier method. Event-free-survival is defined as the time from randomisation to treatment failure (relapse, second malignancy or remission failure) or death. Overall survival denotes the percentage of patients survived for a certain period of time since diagnosis or treatment completion. Statistical significance between NPM1-wild type and NPM1-mutated groups with clinical and cytogenetic characteristics was determined by Fischer's exact test.

\section{Results}

\section{Patients Characteristics}

The laboratory and clinical characteristics between the NPM1-mutated group and the NPM1-wild type group of patients were compared. The NPM1 mutations were present in patients with AML M1 and M2 FAB subtypes. There was no significant difference in the prevalence of NPM1 mutations between sexes. In addition, the mutations were not particularly associated with higher white blood cell count (WBC) or increased blast percentage. However, there was a significant difference with regard to age. The median age in NPM1-mutated group was 10.5 years and in NPM1-unmutated group was 6.5 years $(p=<0.001)$. The study of possible ethnic differences related to the disease was not feasible, due to limited number of patients.

\section{Cytogenetic analysis}

In this study, chromosomal aberrations were observed in $12 / 25(48 \%)$ cases. In 4/12 (33.3\%) patients $t(8 ; 21)$ (q22; q22) was detected, which was principally associated with the AML M2 FAB subtype (75\%). This chromosomal abnormality occurred predominantly in children older than 3 years of age $(18.2 \%)$ and in $16 \%$ of the whole AML population. $M L L$ gene rearrangements with chromosome 11q23 abnormality were detected in 3/12 (25\%) cases; one AML M4 and one M5 newly diagnosed patient with $\mathrm{t}(9 ; 11)(\mathrm{p} 22 ; \mathrm{q} 23)$ and one M4 with $\mathrm{t}(6 ; 11)(\mathrm{q} 27 ; \mathrm{q} 23)$. The $M L L$ gene rearrangements were more common in children younger than 3 years of age $(2 / 3,66.7 \%)$. No NPM1 mutations were found in cases with positive $M L L$ gene rearrangements.

\section{Molecular analysis of gene mutations}

NPM1 gene mutations were detected in 2/25 (8\%) patients with AML (2/18 patients were de novo AML; one M1 AML and one M2 AML newly diagnosed). One of the NPM1 mutations involved multiple base pair substitutions rather than the common 4 base pair insertions. More specifically, the patient acquired a $\mathrm{T} \rightarrow \mathrm{G}$ mutation at codon 290 , which resulted in a substitution 
of tryptophan 290 for glycine (W290) and a $\mathrm{T} \rightarrow \mathrm{C}$ mutation at codon 293, which resulted in a substitution of serine 293 for proline (S293). This patient also carried a $\mathrm{t}(8 ; 21)$ (q22;q22) chromosomal abnormality. The other case involved a type 'A' mutation; a 4-base pair insertion at position nucleotide 960 (Table 1). In our study, there was no significant difference in the frequency of the NPM1 mutations in the AML cases with a normal karyotype (7.7\%) compared to cases with abnormal karyotype $(8.3 \%)$. Of note, a normal karyotype was detected in $13 / 25(52 \%)$ of the AML cases.

\section{Analysis of NPM1 mutations compared to FLT3 and RAS mutations}

All cases were analyzed for FLT3/ITD and FLT3/AL mutations, whereas only the two NPM1 mutant cases were screened for NRAS, KRAS and HRAS mutations. No common RAS mutations among the NPM1-mutated cases were observed. Overall, FLT3/ITD mutations were found in $3 / 25$ (12\%) of AML patients ( $2 / 3$ newly diagnosed). Of these, 1 patient also had an NPM1 mutation. No FLT3/AL mutations were detected.

\section{EFS \& OS}

The EFS and OS at 5-years were estimated at 55.55\% $(\mathrm{SE} \pm 3.25 \%)$ (Figure 1$)$ and $61.70 \%(\mathrm{SE} \pm 4.1 \%)$, respectively. Comparison between the NPM1-mutated group and the NPM1-wild type group was not feasible, since the NPM1 mutated group was composed of only 2 cases, one of which was newly diagnosed.

\section{Discussion}

The current study attempted to assess the incidence and prognostic relevance of NPM1 mutations in childhood AML. NPM1 mutations were found in patients with de novo AML M1 and M2 subtypes. No mutations were observed in patients with AML M5 FAB subtypes, which comprised the larger group in this study. Previous studies in childhood AML also suggested absence of NPM1 mutations in M5 cases [2,16]. In concurrence with other reports $[1,4,7]$, there was no significant association between NPM1 mutations and sex, high WBC or increased blast percentage in the bone marrow at diagnosis.
NPM1 mutations were found in patients above 3 years of age. This is in agreement with previous studies that have also demonstrated a trend towards higher probability of NPM1 mutations for older AML pediatric patients $[1,4,17]$. Rau and Brown [17] proposed the possibility of a relative myeloid progenitor cell resistance to NPM1 mutations in younger pediatric patients.

In our study, $\mathrm{t}(8 ; 21)(\mathrm{q} 22 ; \mathrm{q} 22)$ was observed in $16 \%$ of the total AML cases and in $33.3 \%$ of the cases bearing a chromosomal aberration. NPM1 mutations were observed in one M2 AML case bearing a $t(8 ; 21)$ (q22; q22). Previous studies suggested that in AML, especially in the M2 subtype, translocation $t(8 ; 21)(\mathrm{q} 22 ; \mathrm{q} 22)$ is one of the most frequent chromosomal abnormalities and can be found in $5-12 \%$ of AML cases [18].

Frequently, translocations involving chromosome $11 \mathrm{q} 23$ can be found in $15-20 \%$ of pediatric AML cases and are, in general, associated with a poor outcome [19]. In line with other work [1], our study demonstrated that translocations involving $M L L$ gene rearrangements with chromosome 11q23 abnormality occurred in $12 \%$ of patients and was more common in children younger than 3 years of age (66.6\%).

Progression of MDS to AML may represent a similar, though, more complicated model for leukemic transformation [20]. In the current study, no NPM1 mutations were detected in cases with secondary AML following MDS, which is in line with previous studies associating absence or low rates of NPM1 mutations in patients with MDS [10,21].

Mutations of the NPM1 gene were present in $8 \%$ of AML cases in this study. This is in agreement with previous reports on childhood AML $[1,4,17]$. More than 40 different types of NPM1 mutations have been detected, with types A, B and D being the most common [7]. In our study, sequencing analysis confirmed the presence of a type 'A' mutation in one NPM1-mutated case. The majority of NPM1 mutations encode mutant proteins that have a novel nuclear export signal (NES) motif inserted at the $\mathrm{C}$-terminus and are thought to play a significant role in the abnormal cytoplasmic localization of the NPM protein. The other mutation obtained in the present study, involved 2 individual base pair substitutions which resulted in 2 amino acid changes (W290)

Table 1 Patients' molecular and clinical characteristics

\begin{tabular}{|c|c|c|c|c|c|c|c|c|c|c|}
\hline $\begin{array}{l}\text { Patient } \\
\text { No. }\end{array}$ & Nucleotide sequences & Sex & $\begin{array}{c}\text { Age } \\
\text { (years) }\end{array}$ & $\begin{array}{l}\text { FAB } \\
\text { Type }\end{array}$ & Karyotype & $\begin{array}{c}M L L \\
\text { rearrangement }\end{array}$ & $\begin{array}{c}F L T 3 \\
\text { mutation }\end{array}$ & WBC & $\begin{array}{l}\text { Blast Count } \\
\text { in BM (\%) }\end{array}$ & Survival \\
\hline $\begin{array}{l}\text { Wild } \\
\text { type }\end{array}$ & \multicolumn{10}{|c|}{ gat ctc tgg cag tgg agg aag tct ctt taa gaa aat ag } \\
\hline 1 & $\begin{array}{c}\text { gat ctc tgt } \mathbf{c t g} g c a \text { gtg gag gaa } \\
\text { gtc tct tta aga aaa tag }\end{array}$ & M & 8 years & M1 & $46, x y$ & $\mathrm{~N}$ & None & 23900 & $85 \%$ & $\begin{array}{l}\text { Complete } \\
\text { Remission }\end{array}$ \\
\hline 2 & $\begin{array}{c}\text { gat ctc tgg cag } \underline{\mathbf{g g g}} \text { agg aag } \underline{\mathbf{c c t}} \\
\mathrm{ctt} \text { taa gaa aat ag }\end{array}$ & $\mathrm{F}$ & $\begin{array}{c}13 \\
\text { years }\end{array}$ & M2 & $\begin{array}{c}46, x \times t(8 ; 21) \\
(q 22 ; q 22)\end{array}$ & $\mathrm{N}$ & FLT3/ITD & 7680 & $60 \%$ & $\begin{array}{l}\text { Complete } \\
\text { Remission }\end{array}$ \\
\hline
\end{tabular}


KAPLAN \& MEIER SURVIVAL CURVE

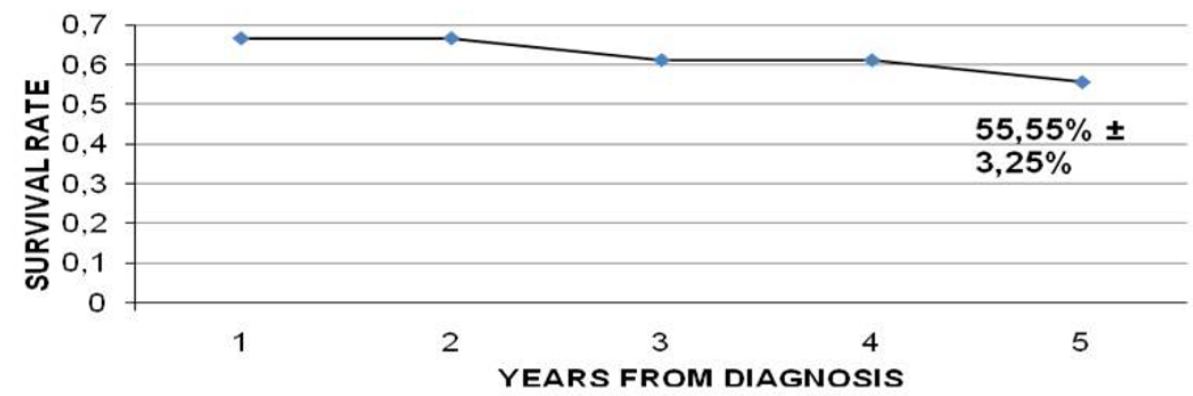

Figure 1 Kaplan and Meier Survival curve.

and (S293) in the NPM protein. To our knowledge, this is a novel mutation, even though disruption of the nucleolar localization signal (NLS) at C-terminus due to mutations in the tryptophan residue 290 has been previously described [17]. More specifically, the tryptophan residue at position 290 is considered essential to the nucleolar localization of the NPM protein [2], however, the overall impact of the presence of both amino acid changes that were detected in our study, remains undefined.

FLT3 gene mutations were identified in $12 \%$ of the total AML cases. This is in line with other studies, in which $11.5 \%$ of the cases carried an ITD mutation in the FLT3 gene [4]. FLT3/ITD mutation was observed in one NPM1-mutated case bearing $\mathrm{t}(8 ; 21)(\mathrm{q} 22 ; \mathrm{q} 22)$. It is not feasible to predict the prognostic value of both mutations in the presence of this translocation, since the time this patient has been monitored is rather short. Rau and Brown [17] and Boonthimat et al. [22] suggested a principal prevalence of FLT3/ITD mutations in NPM1-mutated cases, due to a possible pathogenic link between these two gene mutations.

No correlation was found between RAS mutations and the frequency of NPM1 mutations. This was similarly observed by Boonthimat et al. [22] who suggested that $N P M 1$ and $R A S$ do not cooperate in the pathogenic model of AML. Of note, NRAS mutations are normally found in AML cases with inv(16), which are essentially mutually exclusive of NPM1 mutations [23].

To conclude, it seems that NPM1 mutations are consistently present in approximately $10 \%$ of childhood AML cases [17]. However the observation of a high variety of NPM1 mutations merits further studies, in order to determine their individual contribution to the pathogenesis of childhood AML and their comprehensible relation to prognosis.

\section{Acknowledgements}

The authors would like to thank Dr. Alexandra L. Perry for editing the manuscript and Mr. George Barakos for assistance with statistical analysis.

\section{Author details}

'University Research Institute for the Study and Treatment of Childhood Genetic and Malignant Diseases, University of Athens, "Aghia Sophia" Children's Hospital, Athens, Greece. ${ }^{2}$ Hematology/Oncology Unit, First Department of Pediatrics, University of Athens, "Aghia Sophia" Children's Hospital, Athens, Greece.

\section{Authors' contributions}

$\mathrm{MB}$ organized the research plan, analyzed data, performed experiments and drafted the paper. CP and KK, carried out part of the experiments. TN and KK provided samples and clinical data and F.T-S coordinated the study, participated in its design and contributed to writing. All authors read and approved the final manuscript.

\section{Competing interests}

The authors declare that they have no competing interests.

Received: 24 August 2010 Accepted: 27 October 2010

Published: 27 October 2010

\section{References}

1. Brown P, Mclntyre E, Rau R, Meshinchi S, Lacayo N, Dahl G, Alonzo TA, Chang M, Arceci RJ, Small D: The incidence and clinical significance of nucleophosmin mutations in childhood AML. Blood 2007, 110:979-985.

2. Thiede C, Koch S, Creutzig E, Steudel C, Illmer T, Schaich M, Ehninger G: Prevalence and prognostic impact of NPM1 mutations in 1485 adult patients with acute myeloid leukemia. Blood 2006, 107:4011-4020.

3. Ahmad F, Mandava S, Das BR: Mutations of NPM1 gene in de novo acute myeloid leukemia: determination of incidence, distribution pattern of two novel mutations in Indian population. Hematol Oncol 2009, 27:90-97.

4. Cazzaniga G, Dell'Oro MG, Mecucci C, Giarin E, Masetti R, Rossi V, Locatelli F, Martelli MF, Basso G, Pession A, Biondi A, Falini B: Nucleophosmin mutations in childhood acute myelogenous leukemia with normal karyotype. Blood 2005, 106:1419-1422.

5. Suzuki T, Kiyoi H, Ozeki K, Tomita A, Yamaji S, Suzuki R, Kodera Y, Miyawaki S, Asou N, Kuriyama K, Yagasaki F, Shimazaki C, Akiyama H, Nishimura M, Motoji T, Shinagawa K, Takeshita A, Ueda R, Kinoshita T, Emi N, Naoe T: Clinical Characteristics and prognostic implications of NPM1 mutations in acute myeloid leukemia. Blood 2005, 106:2854-2861.

6. Jeong EG, Lee SH, Yoo NJ, Lee SH: Absence of nucleophosmin 1 (NPM1) gene mutations in common solid cancers. APMIS 2005, 115:341-346.

7. Ruan GR, Li JL, Qin YZ, Li LD, Xie M, Chang Y, Zhang Y, Liu YR, Jiang B, Chen SS, Huang XJ: Nucleophosmin mutations in Chinese adults in acute myelogenous leukemia. Ann Hematol 2009, 88:159-166.

8. Falini B, Mecucci C, Tiacci E, Alcalay M, Rosati R, Pasqualucci L, La Starza R, Diverio D, Colombo E, Santucci A, Bigerna B, Pacini R, Pucciarini A, Liso A, Vignetti M, Fazi P, Meani N, Pettirossi V, Saglio G, Mandelli F, Lo-Coco F, Pelicci PG, Martelli MF, GIMEMA Acute Leukemia Working Party: Cytoplasmic nucleophosmin in acute myelogenous leukemia with a normal karyotype. N Engl J Med 2005, 352:254-266.

9. Chou WC, Tang JL, Lin LI, Yao M, Tsay W, Chen CY, Wu SJ, Huang CF, Chiou RJ, Tseng MH, Lin DT, Lin KH, Chen YC, Tien HF: Nucleophosmin 
mutations in de novo acute myeloid leukemia: The age-dependent indices and the stability during disease evolution. Cancer Res 2006, 66:3310-3316

10. Zhang Y, Zhang M, Yang L, Xiao Z: NPM1 mutations in myelodysplastic syndromes and acute myeloid leukemia with normal karyotype. Leuk Res 2007, 31:109-111.

11. Schnittger S, Schoch C, Kern W, Mecucci C, Tschulik C, Martelli MF, Haferlach T, Hiddemann W, Falini B: Nucleophosmin gene mutations are predictors of favorable prognosis in acute myelogenous leukemia with a normal karyotype. Blood 2005, 106:3733-3739.

12. Syampurnawati M, Tatsumi E, Ardianto B, Takenokuchi M, Nakamachi Y, Kawano S, Kumagai S, Saigo K, Matsui T, Takahashi T, Nagai K, Gunadi , Nishio $H$, Yabe $H$, Kondo $S$, Hayashi Y: DR negativity is a distinctive feature of M1/M2 AML cases with NPM1 mutation. Leuk Res 2008, 32:1141-1143.

13. Stirewalt DL, Radich JP: The role of FLT3 in hematopoietic malignancies. Nat Rev Cancer 2003, 3:650-665.

14. Döhner K, Schlenk RF, Habdank M, Scholl C, Rücker FG, Corbacioglu A Bullinger L, Fröhling S, Döhner H: Mutant nucleophosmin (NPM1) predicts favorable diagnosis in younger adults with acure myeloid leukemia and normal cytogenetics: interaction with other gene mutations. Blood 2005, 106:3740-3746.

15. Braoudaki M, Karpusas M, Katsibardi K, Papathanassiou Ch, Karamolegou K, Tzortzatou-Stathopoulou F: Frequency of FLT3 mutations in childhood acute lymphoblastic leukemia. Med Oncol 2009, 26:460-462.

16. Thiede C, Creutzig E, Reinhardt D, Ehninger G, Creutzig U: Different types of NPM1 mutations in children and adults: evidence for an effect of patient age on the prevalence of TCTG-tandem duplication in NPM1exon 12. Leukemia 2007, 21:366-367.

17. Rau R, Brown P: Nucleophosmin (NPM1) mutations in adult and childhood acute myeloid leukemia: towards definition of a new leukemia entity. Hematol Oncol 2009, 27:171-181.

18. Linggi B, Müller-Tidow $C$, van de Locht $L, H u M$, Nip J, Serve H, Berdel WE, van der Reijden B, Quelle DE, Rowley JD, Cleveland J, Jansen JH, Pandolfi PP, Hiebert SW: The $\mathrm{t}(8 ; 21)$ fusion protein, AML1 ETO, specifically represses the transcription of the p14(ARF) tumor suppressor in acute myeloid leukemia. Nat Med 2002, 8:743-750.

19. Raimondi SC, Chang MN, Ravindranath Y, Behm FG, Gresik MV, Steuber CP, Weinstein HJ, Carroll AJ: Chromosomal abnormalities in 478 children with acute myeloid leukemia: clinical characteristics and treatment outcome in a cooperative pediatric oncology group study-POG 8821. Blood 1999, 94:3707-3716.

20. Pedersen-Bjergaard J, Andersen MK, Christiansen DH, Nerlov C: Genetic pathways in therapy-related myelodysplasia and acute myeloid leukemia. Blood 2002, 99:1909-1912.

21. Shiseki M, Kitagawa $Y$, Wang $Y H$, Yoshinaga $K$, Kondo T, Kuroiwa $H$, Okada M, Mori N, Motoji T: Lack of nucleophosmin mutation in patients with myelodysplastic syndrome and acute myeloid leukemia with chromosome 5 abnormalities. Leuk Lymphoma 2007, 48:2141-2144.

22. Boonthimat C, Thongnoppakhun W, Auewarakul CU: Nucleophosmin mutation in the Southeast Asian acute myeloid leukemia: eight novel variants, FLT3 coexistance and prognostic impact of NPM1/FLT3 mutations. Hematologica 2008, 93:1565-1569.

23. Verhaak RG, Goudswaard CS, van Putten W, Bijl MA, Sanders MA, et al: Mutations in nucleophosmin (NPM1) in acute myeloid leukemia (AML): association with other abnormalities and previously established gene expression signatures and their favorable prognostic significance. Blood 2005, 106:3747-3754.

doi:10.1186/1756-8722-3-41

Cite this article as: Braoudaki et al:: The frequency of NPM1 mutations in childhood acute myeloid leukemia. Journal of Hematology \& Oncology 2010 3:41.

\section{Submit your next manuscript to BioMed Central and take full advantage of:}

- Convenient online submission

- Thorough peer review

- No space constraints or color figure charges

- Immediate publication on acceptance

- Inclusion in PubMed, CAS, Scopus and Google Scholar

- Research which is freely available for redistribution

Submit your manuscript at www.biomedcentral.com/submit
Biomed Central 